\title{
A new perspective on calmodulin-regulated calcium and ROS homeostasis upon carbon black nanoparticle exposure
}

\author{
Nisha Verma ${ }^{1}$ (D) Mario Pink ${ }^{1} \cdot$ Simone Schmitz-Spanke ${ }^{1}$
}

Received: 22 October 2020 / Accepted: 18 March 2021 / Published online: 27 March 2021

(c) The Author(s) 2021

\begin{abstract}
Toxicological studies propose that exposure to carbon black nanoparticles induces organ injuries and inflammatory responses. Besides, current understanding of the molecular mechanisms implies that carbon black nanoparticles (CBNP) exposure induces the production of reactive oxygen species (ROS) causing inflammation, mitochondrial dysfunction or disturbance in calcium homeostasis. However, the precise mechanisms whereby CBNP exert these effects in the lung are still not fully understood. To gain insight into the possible mechanism of CBNP exerted toxicity, human alveolar epithelial cells (A549) were exposed to different concentrations of CBNP and for different timepoints. The reaction of the cells was monitored by the systematic use of cell-based measurements of calcium and ROS, in the presence and absence of calcium $\left(\mathrm{Ca}^{2+}\right)$ pump inhibitors/chelators and antioxidants. Followed by an in-depth PCR analysis of 84 oxidative stress-related genes. The measurements revealed, as compared to the control, that exposure to CBNP nanoparticles leads to the generation of high ROS levels, as well as a disturbance in calcium homeostasis, which remained primarily unchanged even after $24 \mathrm{~h}$ of exposure. Nevertheless, in presence of antioxidants $N$-acetylcysteine (NAC) and Trolox, ROS formation was considerably reduced without affecting the intracellular calcium concentration. On the other hand, $\mathrm{Ca}^{2+}$ pump inhibitors/chelators, BAPTA (1,2-bis(oamino phenoxy)ethane-N, N, N', $\mathrm{N}^{\prime}$-tetraacetic acid) and verapamil not only decreased the $\mathrm{Ca}^{2+}$ overload, but also further decreased the ROS formation, indicating its role in CBNP-induced oxidative stress. Further, a PCR array analysis of A549 cells in presence and absence of the calmodulin $(\mathrm{CaM})$ antagonist $\mathrm{W} 7$, indicated toward nine altered oxidative stress-related genes which further confirmed our cytotoxicity results. Obtained data suggested that CBNP exposure elevates calcium ion concentration, which further contributes to oxidative stress, via the calcium-binding protein CaM. Its inhibition with W7 leads to downregulation in gene expression of nine oxidative stress-related genes, which otherwise, as compared to control, show increased gene expression. The results of the study thus confirm that exposure of lung epithelial cells to CBNP leads to oxidative stress; however, the oxidative stress itself is a result of a disturbance in both calcium and ROS homeostasis, and should be considered while searching for a new strategy for prevention of CBNP-induced lung toxicity.
\end{abstract}

Keywords Carbon black nanoparticles $\cdot$ Reactive oxygen species (ROS) $\cdot$ Calcium homeostasis $\cdot$ Mitochondrial ROS

\section{Introduction}

Scientific and industrial attainments within the last few years have led to discoveries in nanotechnology which were far beyond the imagination of mankind half a century ago (Jeevanandam et al. 2018). Globally, scientists are still discovering the unique properties of daily used materials at

Nisha Verma

nishaverma24@gmail.com

1 Institute and Outpatient Clinic of Occupational, Social and Environmental Medicine, University of ErlangenNuremberg, Henkestrasse 9-11, 91054 Erlangen, Germany the sub-micrometer range domain. Among others, carbon black nanoparticles (CBNP) are identified as one of the most industrial manufactured chemicals due to their widespread applications in automobile, printing, and paint industry (Uddin 2017). Studies suggest that on average, workers encounter approximately one million tons of CBNP (used as raw material) thus raising serious health concerns (Sharma 2010). Due to their particulate size, these particles can be easily dispersed in the ambient conditions and can be readily inhaled thus causing lung diseases (Vesterdal et al. 2010) (Saputra et al. 2014; Umezawa et al. 2018).

Particularly, exposure to high concentrations of nanoparticles is known to impair lung clearance by macrophages 
(Gustafson et al. 2015). The overloading of the lung thus can initiate a severe inflammatory response, which ultimately leads to downstream events like lung fibrosis, and upstream events such as oxidative stress (Gustafson et al. 2015).

Oxidative stress is one of the most known and reported toxicities which the cells encounter when exposed to nanoparticles (Niranjan and Thakur 2017). High ROS levels thus generated are known further to cause severe cell damage which ultimately leads to cell death. However, often this switch is mediated by calcium signaling (Huang et al. 2017). Disturbance in calcium homeostasis upon nanoparticle exposure has been reported in many studies, (Holme et al. 2019; Prada et al. 2017), but a mutual interplay of ROS and calcium ions upon nanoparticle exposure has hardly been explored (Stone et al. 2000). Increasing evidence suggests that interactions between calcium and ROS are necessary for signaling and proper functioning of cellular signaling networks (Görlach et al. 2015; Hempel and Trebak 2017; Yan et al. 2006).

The current study, therefore, explores this interplay of ROS and calcium signaling upon CBNP exposure to understand the pathomechanism behind the CBNP-induced lung toxicity. To achieve our aim, a systematic analysis of disturbance in calcium and ROS homeostasis upon CBNP exposure was carried out in human alveolar epithelial cell line (A549). The cells were exposed to well-characterized and commercially available carbon black nanoparticle Printex 90 in presence and absence of $\mathrm{Ca}^{2+}$ pump inhibitors/chelators and antioxidants. Concentration ranging from 2 to $250 \mu \mathrm{g} /$ $\mathrm{mL}$ and exposure time of 3,6 and $24 \mathrm{~h}$ were tested to comprehensively evaluate the response of CBNP in A549 cells. Finally, to understand the interplay of ROS and calcium signaling at the molecular level, a PCR array analysis of genes involved in oxidative stress, in presence and absence of calcium-regulated protein calmodulin $(\mathrm{CaM})$ was carried out.

\section{Material and methods}

\section{Reagents}

Standard chemicals for cell culture (fetal calf serum (FCS), penicillin/streptomycin and L-glutamine) were purchased from c.c.pro (Oberdorla, Germany). Carbon black (Printex 90) was provided by Evonik (former Degussa, Germany). The fluorescent dyes 2',7'-dichlorodihydrofluorescein diacetate $\left(\mathrm{H}_{2} \mathrm{DCFDA}\right)$, Fluo-4/AM and Rhod-2/AM and MitoSox Red were acquired from Invitrogen ${ }^{\mathrm{TM}}$ (Darmstadt, Germany). RNeasy Plus Mini Kit, RT $^{2}$ First Strand Kit and the Human Oxidative Stress Plus RT2 Profiler PCR array (PAHS-065Z) were purchased from (Qiagen, Hilden, Germany).

\section{Cell culture and carbon black nanoparticle exposure}

The human alveolar epithelial cells (A549, ATCC® CCL$185^{\mathrm{TM}}$ ) were cultured until confluency in Dulbecco's Modified Eagle Medium, supplemented with $10 \%$ (v/v) FCS, $7.4 \mathrm{mg} / \mathrm{mL}$ L-glutamine, 100 units $/ \mathrm{mL}$ penicillin, and $100 \mathrm{mg} / \mathrm{mL}$ streptomycin at $37^{\circ} \mathrm{C}$ in a humidified atmosphere of $95 \%$ air and $5 \% \mathrm{CO}_{2}$. After $24 \mathrm{~h}$ of culture, cells were exposed to varying concentration of CBNP for further 3, 6 and $24 \mathrm{~h}$.

\section{Preparation of particles}

CBNP were weighed and suspended in the culture media to obtain a stock solution of $1 \mathrm{mg} / \mathrm{mL}$. The stock solution was then sonicated in a water bath for $5 \mathrm{~min}$. The nanoparticles suspension obtained was subsequently diluted 1:2(v/v) with the cell culture medium to achieve the nominal concentrations. The nanoparticles dilutions were sonicated to distribute the nanoparticles as homogeneously as possible, before adding them to the cells.

\section{Determination of hydrodynamic size and zeta potential of CBNP}

The particle size distribution of CBNP was measured using dynamic light-scattering (Nano Zetasizer ZS; Malvern Instruments, Worcestershire, UK) after suspending the nanoparticles in the cell culture medium, using an ultrasonic water bath for $5 \mathrm{~min}$ at room temperature. Zeta potential values were obtained using the Smoluchowski model for analysis. In brief, $1 \mathrm{~mL}$ dispersions of CBNP $(100 \mu \mathrm{g} / \mathrm{mL})$ in culture media were prepared in cuvettes and analyzed after $24 \mathrm{~h}$ of dispersion. The samples were analyzed in triplicates. Calibration and blank samples were analyzed prior to all measurements.

\section{Determination of cellular reactive oxygen species (ROS) level}

The production of ROS by A549 cells was measured using the fluorescent dye $2^{\prime}, 7^{\prime}$-dichlorodihydrofluorescein diacetate $\left(\mathrm{H}_{2} \mathrm{DCFDA}\right.$; Invitrogen). For the experiment, 25,000 cells $/ \mathrm{mL}$ were seeded into 96 -well plates. $24 \mathrm{~h}$ after seeding, cells were exposed to different CBNP nominal concentrations ranging from 2 to $250 \mu \mathrm{g} / \mathrm{mL}$ for 3,6 and $24 \mathrm{~h}$. Cells treated with cell culture medium were used as negative 
control, while $100 \mu \mathrm{M}$ of $\mathrm{H}_{2} \mathrm{O}_{2}$ served as a positive control. For ROS measurement, the cells were then washed with HBSS buffer ( $\mathrm{pH}$ 7.2), and incubated with $10 \mu \mathrm{M}$ $\mathrm{H}_{2}$ DCFDA in HBSS (pH 7.2) for $30 \mathrm{~min}$ at $37^{\circ} \mathrm{C}$. The fluorescence intensity was measured at an excitation wavelength of $485 \mathrm{~nm}$ and an emission wavelength of $535 \mathrm{~nm}$.

In a separate series of experiments, to determine whether ROS generation due to CBNP exposure in these cells was responsible for increased calcium concentrations, calcium measurements (as described below) were performed in the cells pre-treated to antioxidants- 6-hydroxy-2,5,7,8-tetramethylkroman-2-carboxyl acid (Trolox) and $\mathrm{N}$-acetylcysteine (NAC). A water-soluble vitamin E analog, Trolox confers protection due to its intracellular scavenging activity (Hamad et al. 2010), whereas, NAC is a synthetic acetylated derivative of amino acid cysteine, and because of its sulfhydryl group acts as a free radical scavenger (Aldini et al. 2018). For the experiment, the cells were preincubated with Trolox $(35 \mu \mathrm{M})$ or NAC $(50 \mu \mathrm{M})$ for $1 \mathrm{~h}$, the incubation medium was then removed, to further incubate cells with CBNP at a final concentration of $125 \mathrm{mg} / \mathrm{mL}$ for another $24 \mathrm{~h} .125 \mu \mathrm{g} / \mathrm{mL}$ concentration of CBNP was chosen because it showed maximum damage, as compared to the control cells. Calcium measurements were then carried out according to the protocols described in the paper.

\section{Determination of intracellular calcium concentration}

To study CBNP-induced changes in calcium homeostasis in different cellular compartments, two $\mathrm{Ca}^{2+}$-sensitive dyes were used: Fluo-4/AM to observe changes in intracellular calcium concentration $\left(\left[\mathrm{Ca}^{2+}\right]_{i}\right)$, and Rhod-2/AM to determine alterations in mitochondrial calcium concentration. 25,000 cells $/ \mathrm{mL}$ were seeded onto 96 well plates. After $24 \mathrm{~h}$ culture, cells were exposed to nominal concentrations of CBNP as described above for 3, 6 and $24 \mathrm{~h}$. After the exposure, cells were washed twice with HBSS ( $\mathrm{pH}$ 7.2) and incubated with acetoxymethyl (AM) ester of Fluo-4/AM $(1.4 \mu \mathrm{M})$ and Rhod-2/AM $(3.6 \mu \mathrm{M})$ in the same buffer for $30 \mathrm{~min}$ at room temperature (RT). The incubation was carried out RT to reduce the subcellular compartmentalization of the dyes, an inherent problem with the AM ester loading techniques. The cells were then further incubation for another $30 \mathrm{~min}$ at $37^{\circ} \mathrm{C}$ to allow complete de-esterification of intracellular AM esters. Subsequently, the dye solution was removed, and the cells were incubated for $30 \mathrm{~min}$ at $37^{\circ} \mathrm{C}$ in HBSS (pH 7.2) (3 mL) supplemented with $2.5 \mathrm{mM}$ probenecid to decrease dye leakage. For calcium measurements, the cells were washed once with pre-heated HBSS $\left(37^{\circ} \mathrm{C}\right)$, and the measurement was performed in same buffer containing probenecid. The green fluorescence of
Fluo-4 was excited at $488 \mathrm{~nm}$ and was collected through a $505-535 \mathrm{~nm}$ bandpass filter, whereas the red fluorescence of Rhod-2, excited at $543 \mathrm{~nm}$, was collected through a $560 \mathrm{~nm}$ long-pass filter.

To determine whether the increase in calcium ions upon CBNP exposure had any effects on ROS levels and its signaling, A549 cells were pretreated with the calcium channel blocker verapamil $(50 \mu \mathrm{M})$, calcium chelator BAPTA-AM (1,2-bis (o-amino phenoxy)ethane- $N, N, N^{\prime}, N^{\prime}$-tetraacetic acid)) $(25 \mu \mathrm{M})$ and calmodulin antagonist W-7 $(N-(6-$ Aminohexyl)-5-chloro-1-naphthalene sulfonamide) $(5 \mu \mathrm{M})$ for $1 \mathrm{~h}$. The incubation medium was then removed, and the cells were further incubated with CBNP at a nominal concentration of $125 \mathrm{mg} / \mathrm{mL}$ for another $24 \mathrm{~h}$. ROS measurements were then carried out according to the protocols described.

\section{Detection of the mitochondrial membrane potential (MMP)}

For the determination of the mitochondrial potential, A549 cells were seeded at a concentration of 25,000 cells $/ \mathrm{mL}$ in 96-well plates for $24 \mathrm{~h}$. After $24 \mathrm{~h}$ culture, the cells were exposed to nominal concentrations of CBNP as described above for 3, 6 and $24 \mathrm{~h}$. After the exposure, cells were washed twice with HBSS buffer ( $\mathrm{pH} 7.2$ ) and incubated with a cationic dye JC-1 (5,5',6,6'-tetrachloro-1,1',3,3'-tetraethyl benzimidazolocarbo-cyanine iodide, $10 \mu \mathrm{M}$ ) in HBSS (pH 7.2) for $30 \mathrm{~min}$ at $37^{\circ} \mathrm{C}$. Cells treated with normal cell culture medium were used as negative controls, while $100 \mu \mathrm{M}$ of the ionophore valinomycin served as positive control. Following incubation with the dye, the cells were washed three times with pre-heated $\left(37{ }^{\circ} \mathrm{C}\right) \mathrm{HBSS}(\mathrm{pH}$ 7.2) and measured immediately. Measurements were obtained as a ratio of red aggregate of JC-1 dye with absorption/emission at 585/590 $\mathrm{nm} /$ green aggregate of the dye, with absorption/emission of $510 / 527 \mathrm{~nm}$ in the mitochondria, using the Tecan microplate reader (Tecan, Mainz, Germany).

\section{Determination of mitochondrial ROS using MitoSOX Red}

Alterations of the mitochondrial ROS levels due to CBNP were measured using a mitochondria-targeted superoxide indicator (MitoSOX Red) dye. Briefly, 25,000 cells $/ \mathrm{mL}$ of A549 cells were seeded in 96-well plates for $24 \mathrm{~h}$. After $24 \mathrm{~h}$ culture, the cells were exposed to nominal concentrations of CBNP, as described above for 3, 6 and $24 \mathrm{~h}$. After the exposure, the cells were washed twice with pre-heated HBSS buffer $\left(37^{\circ} \mathrm{C}, \mathrm{pH} 7.2\right)$ and further incubated with the same buffer containing MitoSOX Red (5 $\left.\mu \mathrm{M}, 10 \mathrm{~min}, 37^{\circ} \mathrm{C}\right)$. 
Following incubation with the dye, the cells were washed three times with pre-heated HBSS $\left(37^{\circ} \mathrm{C}, \mathrm{pH} 7.2\right)$ and measured immediately using the Tecan microplate reader (Tecan, Mainz, Germany) at an excitation wavelength of $510 \mathrm{~nm}$ and an emission wavelength of $580 \mathrm{~nm}$.

\section{RNA isolation}

Total RNA from exposed and unexposed A549 cells $\left(1.5 \times 10^{6} / \mathrm{mL}\right)$ was isolated using the Qiagen's RNeasy Plus Mini Kit (Qiagen, Hilden, Germany). Experiments were performed considering four replicates. Genomic DNA was removed from each sample by treatment with rDNase at $37{ }^{\circ} \mathrm{C}$ for $20 \mathrm{~min}$ (Qiagen, Hilden, Germany). RNA quality was assessed using analysis on a $2 \%$ agarose gel, while the concentrations were determined using a NanoDrop 2000 spectrophotometer (Thermo Fisher Scientific). The $260 \mathrm{~nm} / 280 \mathrm{~nm}$ absorbance ratios of all samples were determined to be $>1.8$. An aliquot of RNA $(1 \mu \mathrm{g})$ was copied into cDNA using an RT ${ }^{2}$ First Strand Kit (Qiagen, Hilden, Germany). The pathway-focused Human Oxidative Stress Plus $\mathrm{RT}^{2}$ Profiler PCR array (Qiagen, 96-well format, catalog no. 35802175370698587056 PAHS-065Z) with 84 oxidative stress-associated genes (Supplementary Table 1) was used to assess the exposure-induced differential gene expression with an ABI 7500 real-time qPCR system (Thermo Fisher Scientific). In brief, $1 \mu \mathrm{g}$ of cDNA was mixed with SYBR Green master mix provided with the kit and dispensed into each well of the PCR array plate containing the pre-dispensed gene-specific primer sets. The PCR was performed according to the manufacturer's instructions. Each PCR array plate contained five housekeeping genes (Actb, Gapdh, Hsp90ab1, Hprt1, Gusb) for normalization of the PCR array data, and one negative control to monitor for genomic DNA contamination. The PCR array also contained three wells of reverse transcription controls (RTC) to verify the efficiency of the RT reaction and replicate positive PCR controls (PPC) to check the efficiency of the polymerase chain reaction, as well as a test for inter-well and intra-plate consistency.

\section{Data analysis}

A comparative or $\Delta \Delta \mathrm{Ct}$ method of qPCR data analysis was performed on $\mathrm{RT}^{2}$ Profiler PCR Array Data Analysis Webportal (https://www.qiagen.com). Transcriptional changes in cells exposed to CBNP were compared to changes in cells pretreated with $\mathrm{CaM}$ to assess its effects on CBNP-induced oxidative stress. Differentially expressed genes were identified using Qiagen $\mathrm{RT}^{2}$ Profiler Data Analysis software, with significance defined as $P<0.05$. The $P$-value adjusted for false discovery rate (FDR) was estimated to be $0.0005(\alpha / \mathrm{n}$; $\alpha=0.05$, and $n=84$ genes). Bioinformatics tool, Search Tool for Interacting Chemicals (STRING) (http://string-db.org/) (von Mering et al. 2003) was used to elucidate the biological pathways associated with the individually identified genes.

\section{Statistical analysis}

All tests were performed in at least four independent experiments. The level of statistical significance relative to control was calculated using the $t$-test. A $P$ value of $<0.05$ was significant.

\section{Results \\ Determination of CBNP size and Z-potential}

The hydrodynamic number-based size distribution revealed a narrow, unimodal peak with an average diameter below $150 \mathrm{~nm}$ for all particle suspensions. The zeta potential was recorded as $-8.92 \mathrm{mV}$ to $-10.7 \mathrm{mV}$.

\section{Effect of CBNP exposure on cellular ROS levels}

Induction of reactive oxygen species upon nanoparticle exposure is considered one of the primary cause of nanoparticles induced toxicity (Fu et al. 2014). A549 cells after $3 \mathrm{~h}$ exposure (Supplementary Fig. 1A), showed minor cellular ROS alterations. However, after $6 \mathrm{~h}$ of exposure (Fig. 1a) at a concentration of $16 \mu \mathrm{g} / \mathrm{mL}$ onwards, a strong concentrationdependent increase in ROS formation with levels $\sim 20-25$ times higher than control (in cells exposed to $250 \mu \mathrm{g} / \mathrm{mL}$ CBNP) was observed. Even after $24 \mathrm{~h}$ of CBNP exposure (Fig. 1b), high ROS levels were maintained although slightly reduced as compared to $6 \mathrm{~h}$ exposure $(\sim 8-18$ times higher than control).

\section{Changes in calcium homeostasis upon CBNP exposure}

Deregulation in $\mathrm{Ca}^{2+}$ homeostasis upon nanoparticle exposure has been reported in many studies. After $3 \mathrm{~h}$ exposure, reasonable increase $(\sim 15 \%)$ in cytosolic and mitochondrial $\mathrm{Ca}^{2+}$ was observed already at moderate exposure concentrations (Supplementary Fig. 1B). Like ROS measurements, after $6 \mathrm{~h}$ of CBNP exposure at a concentration of $16 \mu \mathrm{g} /$ 


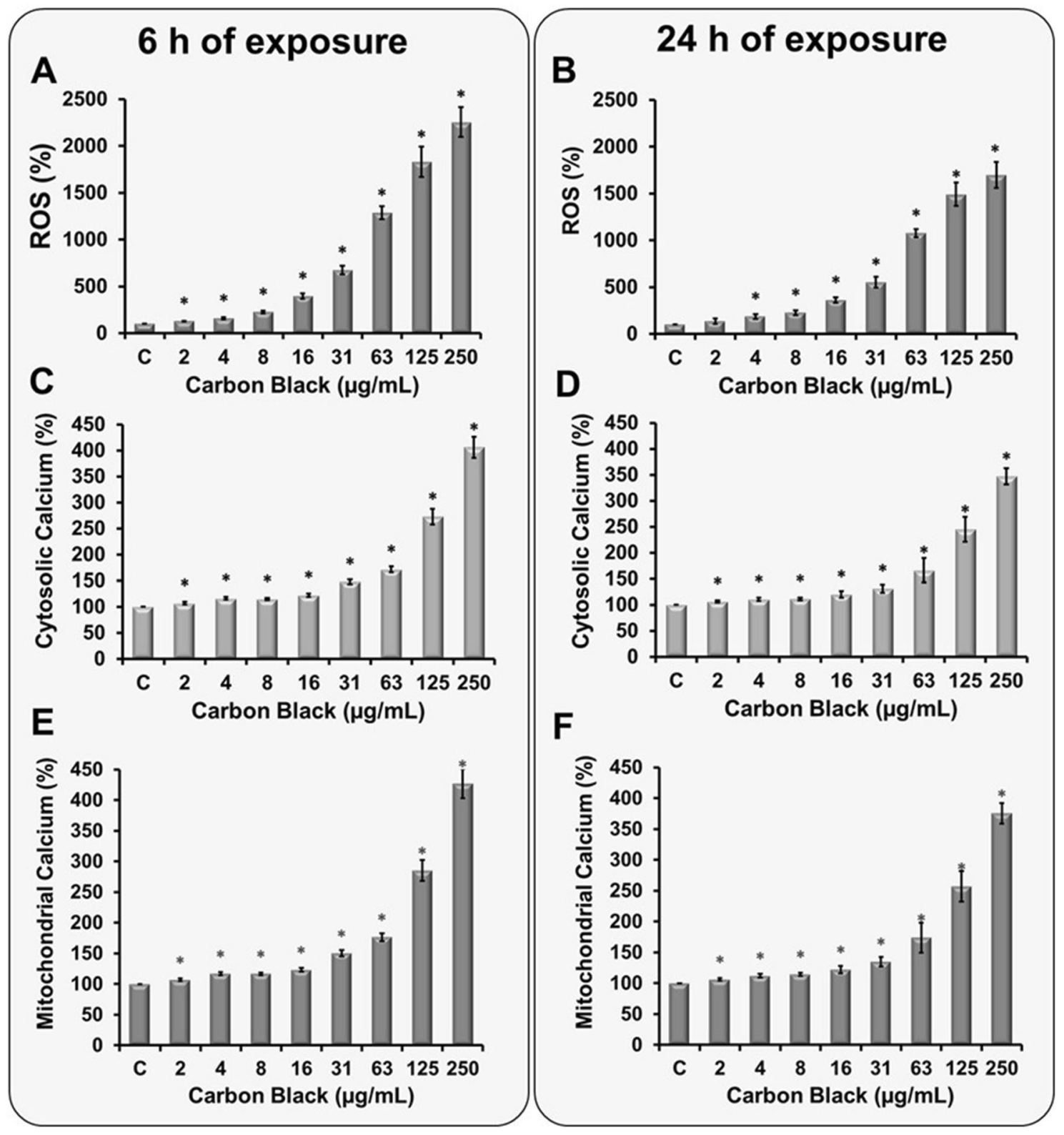

Fig. 1 Alterations in cellular ROS and calcium homeostasis after exposure to CBNP. ROS measurements were made in cells exposed to different concentrations of CBNP ( 2 to $250 \mu \mathrm{g} / \mathrm{mL}$ ) for 6 (a) and $24 \mathrm{~h}$ (b) using fluorescent dye $\mathrm{H}_{2}$ DCFDA. $\mathrm{H}_{2} \mathrm{O}_{2}(100 \mu \mathrm{M})$ was used as a positive control. Data are expressed as the percentage of ROS levels in exposed cells as compared to unexposed cells arbitrarily set to $100 \%$. Spectrofluorometric cytosolic $(\mathbf{c}-6 \mathrm{~h}, \mathbf{d}-24 \mathrm{~h})$ and mito-

chondrial (e-6 h, f-24 h) calcium measurements were made in A549 cells exposed to 2 to $250 \mu \mathrm{g} / \mathrm{mL}$ CBNP using Fluo-4/AM and Rhod-2/AM dyes. Data are expressed as the percentage of calcium levels found in treated cells as compared to untreated cells arbitrarily set to $100 \%$. The data are presented as mean \pm standard deviation of four independent experiments. The level of significance relative to the control was determined using $t$-test $(* P<0.05, * * * P<0.001)$

$\mathrm{mL}$ onwards, a concentration-based increase in cytosolic and mitochondrial $\mathrm{Ca}^{2+}$ (Fig. 1c, e) was observed. In contrast to ROS, after $24 \mathrm{~h}$ exposure, the cellular calcium levels remained primarily unchanged compared to the $6 \mathrm{~h}$ results, 3.5 times as compared to the control (Fig. 1d-f).

\section{The interplay of cellular ROS and $\mathrm{Ca}^{2+}$ upon CBNP exposure}

An interplay between ROS and calcium ions has been reported upon exposure to nanoparticles (Stone et al. 2000). In A549 cells, a modulation of intracellular ROS and calcium levels upon CBNP exposure was also observed. To analyze this interdependence in A549 cells, 
ROS measurements were carried out in presence of $\mathrm{Ca}^{2+}$ pump inhibitor verapamil, calcium chelator BAPTA and calcium measurements in presence of antioxidants NAC and Trolox (Supplementary Fig. 2). A significant increase in ROS levels was detected in cells treated with CBNP. When the cells were pretreated with NAC and Trolox, the production of ROS induced by CBNP was effectively reduced to $58 \%$ and $73 \%$, respectively. Thus, suggesting that cytotoxic effect of CBNP in A549 cells to a great extent was exerted by ROS generation (Fig. 2a); however, it had no effect on intracellular calcium concentration (Fig. 2b). In the second set of experiments, $\mathrm{Ca}^{2+}$ pump inhibitors/chelators, BAPTA and verapamil pretreatment of the cells not only decreased the $\mathrm{Ca}^{2+}$ overload by $17 \%$ and 26\%, respectively, (Fig. 2d) but also further decreased ROS levels by $35 \%$ in BAPTA treated cells, and $51 \%$ in verapamil pretreated cells (Fig. 2c). The results of this experiment indicated that an increase in calcium levels upon CBNP exposure involved the mobilization of calcium from both intracellular stores and extracellular influx, but most importantly contributed to the increased ROS levels upon CBNP exposure.

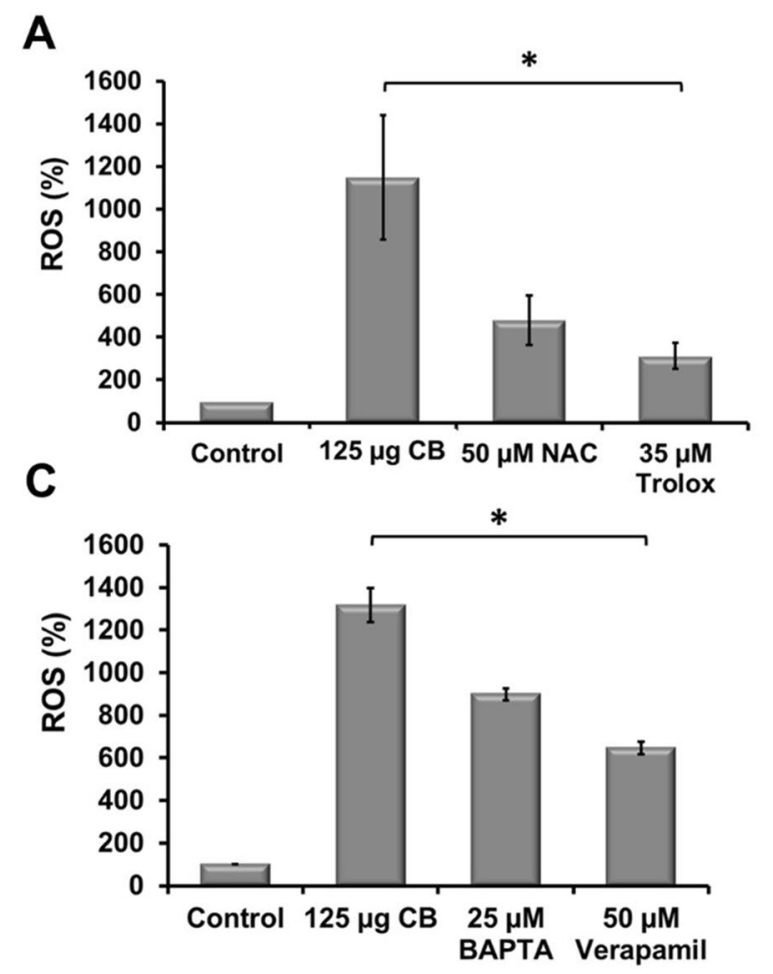

Fig. 2 Interaction between ROS and $\mathrm{Ca}^{2+}$ upon CBNP exposure. $\mathrm{CB}$ exposed cells showed increased levels of ROS and intracellular $\mathrm{Ca}^{2+}$. a The antioxidants $\mathrm{N}$-acetylcysteine (NAC) and Trolox reduced ROS levels, without affecting the intracellular calcium concentration $\mathbf{b}$. On the other hand, $\mathbf{c ~} \mathrm{Ca}^{2+}$ pump inhibitors/chelators not only decreased

\section{The possible role of calmodulin}

To elucidate the role of CaM in the interplay between ROS and calcium, ROS measurements were carried out in the presence and absence of $\mathrm{CaM}$ inhibitor W-7. The exposure of A549 cells to CBNP $(125 \mu \mathrm{g} / \mathrm{mL})$ led to 15 times more ROS in exposed cells as compared to control, however upon blocking of CaM by its inhibitor W-7, the exposed cells exhibited a sharp drop in ROS levels by $50 \%$. Thus, indicating its role, and thereby of calcium, in the regulation of ROS generated upon CBNP exposure in a CaM dependent manner (Fig. 3).

\section{Analysis of mitochondrial function upon CBNP exposure}

As visible in Supplementary Fig. 1C, during the initial $3 \mathrm{~h}$ of exposure, the MMP of the cells remained unaltered. However, after $6 \mathrm{~h}$ exposure, as indicated by the increase of red to green ratio, the cells exhibited hyperpolarization of the mitochondria at higher concentration

B
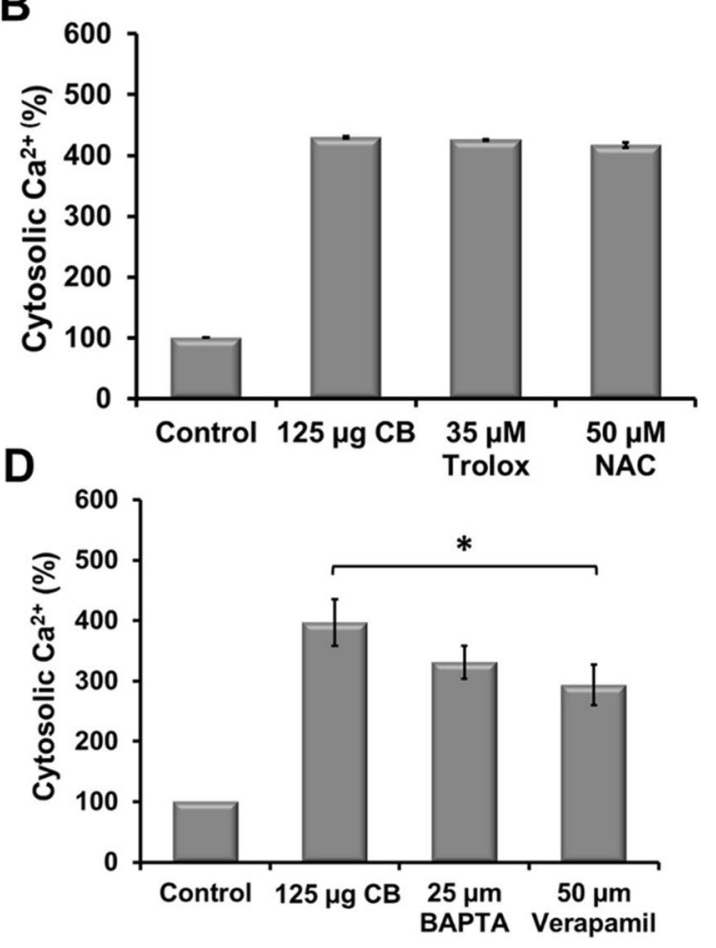

the $\mathrm{Ca}^{2+}$ overload, but also further decreased ROS levels d, indicating its role in CB-induced oxidative stress. The data is presented as mean \pm standard deviation of four independent experiments. The level of significance relative to the carbon black exposure was determined using $t$-test $(* P<0.05, * * * P<0.001)$ 


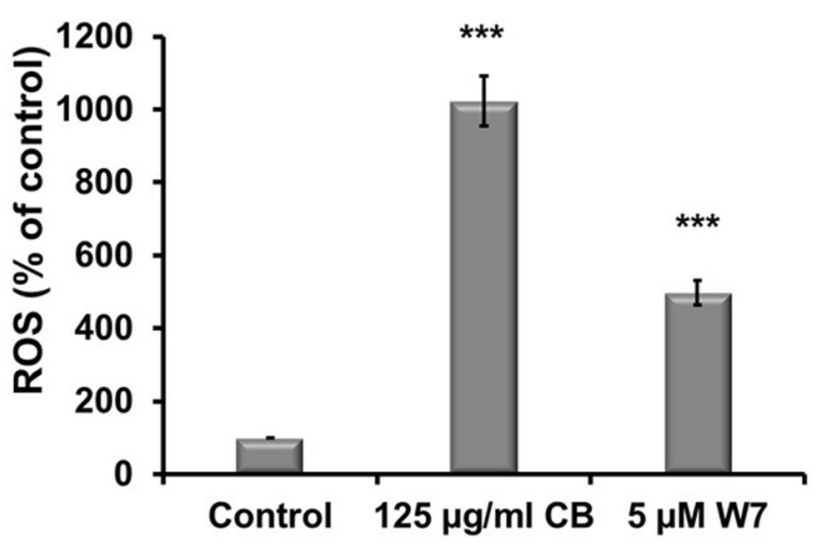

Fig. 3 Effect of calmodulin inhibition on ROS levels. To elucidate the role of $\mathrm{CaM}$ in the interplay between ROS and calcium, ROS measurements were carried out in the presence and absence of $\mathrm{CaM}$ inhibitor W-7. A549 cells were cultured on a clear bottom 96 well plate and were pre-exposed to calcium antagonist, W-7 ( $N-(6-$ Aminohexyl)-5-chloro-1-naphthalene sulfonamide) $(5 \mu \mathrm{M})$ for $1 \mathrm{~h}$. The incubation medium was then removed, and cells were further incubated with CBNP at a nominal concentration of $125 \mathrm{mg} / \mathrm{mL}$ for another $24 \mathrm{~h}$. ROS measurements were then made at an excitation wavelength of $485 \mathrm{~nm}$ and an emission wavelength of $535 \mathrm{~nm}$. The data are presented as mean \pm standard deviation of four independent experiments. The level of significance relative to the carbon black exposure was determined using $t$-test $(* P<0.05, * * * P<0.001)$

of CBNP exposure (63 to $250 \mu \mathrm{g} / \mathrm{mL}$ exposure concentrations, Fig. 4a). With a significant increase of $30 \%$ (in cells exposed to $250 \mu \mathrm{g} / \mathrm{mL}$ of CBNP) as compared to control (Fig. 4a). However, after $24 \mathrm{~h}$ of exposure, a slight depolarization of the MMP was observed at lower exposure concentration ( 8 to $63 \mu \mathrm{g} / \mathrm{mL}$ ), whereas at higher exposure concentration ( 125 and $250 \mu \mathrm{g} / \mathrm{mL}$ ) of CBNP the mitochondria returned to the hyperpolarized state (Fig. 4b).

\section{Effect of CBNP exposure on mitochondrial ROS levels}

It was observed that CBNP exposure in A549 led to mitochondria dysfunction. To analyze its influence on mitochondrial generated ROS, the fluorogenic dye MitoSox Red was used. As evident from the Fig. 4c, d, a concentration and time-dependent increase in mitochondrial ROS was observed. After $24 \mathrm{~h}$ exposure (Fig. 4d), an increase of up to $20 \%$ was already observed at lower exposure concentrations such as $4 \mu \mathrm{g} / \mathrm{mL}$, while at higher concentration $(250 \mu \mathrm{g} / \mathrm{mL})$, a significant increase of $40 \%$ as compared to control was observed.

\section{Transcriptional profiling of oxidative stress-related genes in CBNP exposed cells in the presence and absence of $\mathrm{W}-7$}

From the experiments, it was observed a possible role of calcium-regulated protein CaM in CBNP-mediated oxidative stress. To translate this effect on the gene level, a PCR array analysis was performed in CBNP treated A549 cells. For this experiment, the samples were separated into two groups other than control. Group 1: A549 cell exposed to CBNP $(125 \mu \mathrm{g} / \mathrm{mL})$ and group 2: A549 cells pretreated with CaM inhibitor W-7.

In-group $1,19 \%$ of the arrayed genes $(n=14)$ showed altered expression in the cells exposed to CBNP when compared to the control group (with a fold change regulation of $\geq 1.5$-fold and a statistical cutoff at $P<0.05$, Supplementary Table 2). The entire identified genes were found to be upregulated. Whereas, in group 2, 18 genes were found to be altered (with a fold change regulation of $\geq 1.5$-fold and a statistical cutoff at $P<0.05$, Supplementary Table 3). Among group 1 and 2 as compared to control, 14 genes involved in the antioxidant system and ROS metabolism were found to be regulated. The genes included members of glutathione peroxidase (GPX2, GPX4, CAT, PRDX5, SOD2, VIMP, PXDN, and MGST3) and ones involved in ROS metabolism (MPV17, UCP2, GTF21, TXND2, CCL5).), whereas three genes (MPO, MT3, and NOS2) were specific for group 2. These genes have been identified for their role in inflammation, their upregulation in absence of calcium protein calmodulin indicates toward the role of calcium in cell protection upon CBNP-induced ROS toxicity.

To analyze the effect of $\mathrm{CaM}$ on CBNP gene regulation, a comparison of group 1 and group 2 was carried out. For comparison, only those genes were considered which showed a positive regulation $(>1.5)$ and a statistical cutoff at $P<0.05$ in group 1 (w/o CaM), and no regulation in group $2(<1.5$-fold, w/o CaM). Based upon the above criteria, a total of nine genes were further selected (Fig. 5a). The selected genes included catalase (CAT), dual specificity phosphatase 1 (DUSP1), general transcription factor IIi (GTF21), microsomal glutathione S-transferase 3 (MGST3), mitochondrial inner membrane protein (MPV17), peroxiredoxin 5 (PRDX5), peroxidase homolog (PXDN), thioredoxin reductase 2 (TXDRD2) and uncoupling protein 2 (mitochondrial, proton carrier, UCP2). Network-based analysis to identify canonical pathways was carried out using the search tool STRING (Fig. 5b). Interestingly, the software associated the differentially expressed genes with a network containing the response to oxidative stress with most of the regulated genes concentrated to mitochondrial location (Fig. 5c). 


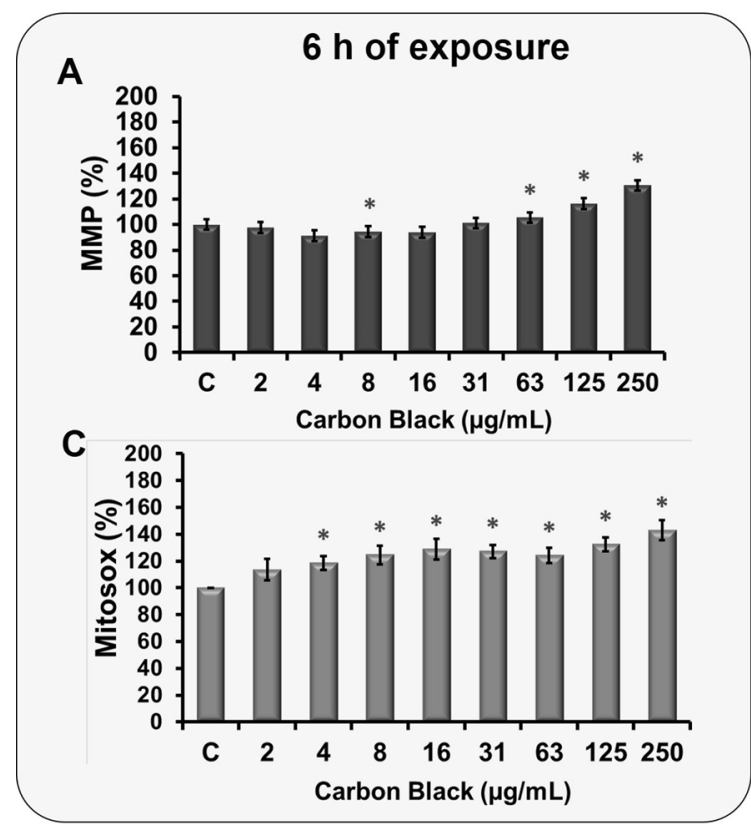

Fig. 4 Changes in mitochondrial membrane potential and generation of mitochondrial ROS on CBNP exposure. a Determination of MMP on A549 cells using the JC-1 dye. Cells were cultured on a clear bottom 96-well plates with a clear bottom and were exposed to $2-250 \mu \mathrm{g} / \mathrm{mL}$ of CBNP for different time periods (6 and $24 \mathrm{~h}$ ). Valinomycin $(100 \mu \mathrm{M})$ was used as a positive control, while at the negative control, cells were exposed to culture medium. JC-1 dye $(5 \mu \mathrm{M})$ was applied for $30 \mathrm{~min}$. Measurements were obtained immediately as a ratio of a red aggregate of JC -1 dye with absorption/emission at $585 / 590 \mathrm{~nm} /$ green aggregate of the dye, with absorption/emission of

Another interesting pathway, which STRING analysis pointed during analysis, was the pathway related to mitogen-activated protein kinase (MAPK) signaling cascade. MAPKs are components of the signaling cascades known to initiate responses involved in cell growth, proliferation, and environmental stress (Cargnello and Roux 2011; Wada and Penninger 2004). The pathway was highlighted due to the alteration of gene DUSP1, which specifically dephosphorylates and inactivates MAPK. The downregulation of the above nine oxidative stress-related genes in absence of calcium suggests the specific contribution of $\mathrm{Ca}^{2+}$ (via generation of mitochondrial ROS) in CBNP-mediated oxidative stress.

\section{Discussion}

The results of the present study provide an evidence that the disturbance in calcium homeostasis upon CBNP exposure in lung epithelial cells plays a pivotal role in generation of reactive oxygen species, and hence over all toxicity caused by CBNP exposure. The present hypothesis is supported by the findings that $\mathrm{Ca}^{2+}$ sequestration with calcium-regulated

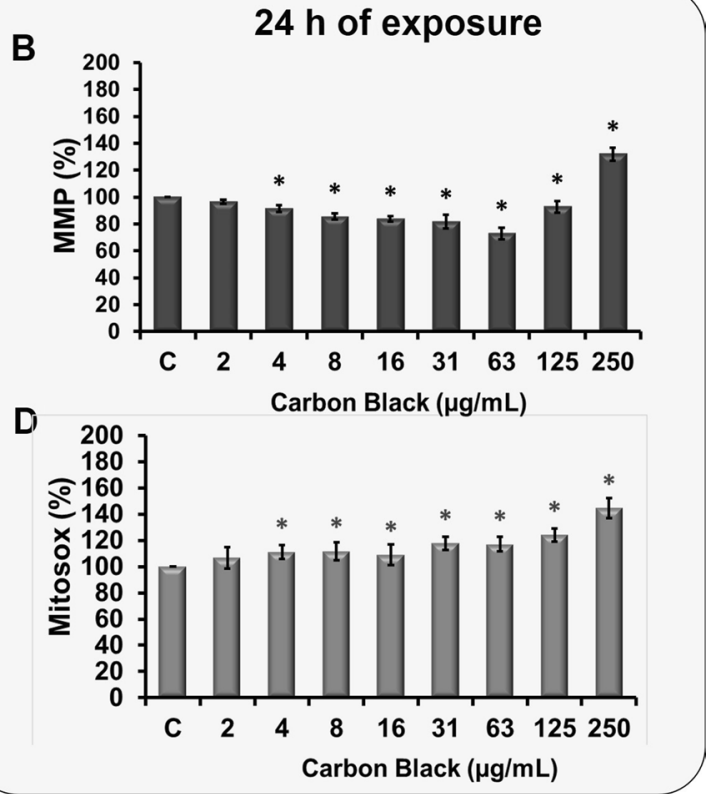

$510 / 527 \mathrm{~nm}$ in the mitochondria using the Tecan microplate reader (Tecan, Mainz, Germany). b Fluorogenic dye MitoSox Red was used to determine the mitochondrial ROS generated upon CBNP exposure, A549 cells were incubated with a buffer containing $5 \mu \mathrm{M}$ MitoSOX Red for $10 \mathrm{~min}$. The measurements were then carried out at an excitation wavelength of $510 \mathrm{~nm}$ and an emission wavelength of $580 \mathrm{~nm}$. The data is presented as mean \pm standard deviation of four independent experiments. The level of significance relative to the positive control was determined using $t$-test $(* * * P<0.001)$

protein $\mathrm{CaM}$ and chelator BAPTA and verapamil, as all prevented the CBNP-induced ROS formation. Gene array analysis further supported these findings and revealed the mitochondrial dysfunction that the cells experience upon CBNP exposure.

\section{Disturbance in calcium homeostasis and the generation of oxidative stress}

The generation of free radicals by CBNP has been well documented (Abdal Dayem et al. 2017; Madl et al. 2014; Manke et al. 2013). The unique surface chemistry, large surface area, and redox-active or catalytic contamination of nanoparticles are known to enable ROS generation (Fu et al. 2014; Gonzalez et al. 2008). CBNP exposure in A549 cells also showed a strong concentration-dependent increase in ROS levels, at nominal concentrations, at which 20 times high ROS levels were recorded as compared to control cells (Fig. 1a, b). Unfortunately, it was not possible to identify specific ROS species generated upon CBNP exposure in A459 cells; however, both antioxidants NAC and Trolox considerably inhibited ROS level, thus suggesting that their 
A

\begin{tabular}{|c|c|c|}
\hline \multirow{2}{*}{$\begin{array}{c}\text { Gene Symbol } \\
\text { CAT }\end{array}$} & $\begin{array}{l}\text { Fold Change (> 1.5) } \\
\text { Group1-CB }\end{array}$ & $\begin{array}{l}\text { Fold Change }(<1.5) \\
\text { Group 2- CB+W7 }\end{array}$ \\
\cline { 2 - 3 } & 1.7023 & 1.4178 \\
\hline DUSP1 & 1.6949 & 1.4237 \\
\hline GTF2I & 1.7000 & 1.4217 \\
\hline MGST3 & 1.7020 & 1.4222 \\
\hline MPV17 & 1.7045 & 1.4218 \\
\hline PRDX5 & 1.6998 & 1.4198 \\
\hline PXDN & 1.6875 & 1.4165 \\
\hline TXNRD2 & 1.6977 & 1.191 \\
\hline UCP2 & 1.6864 & 1.414 \\
\hline
\end{tabular}

B

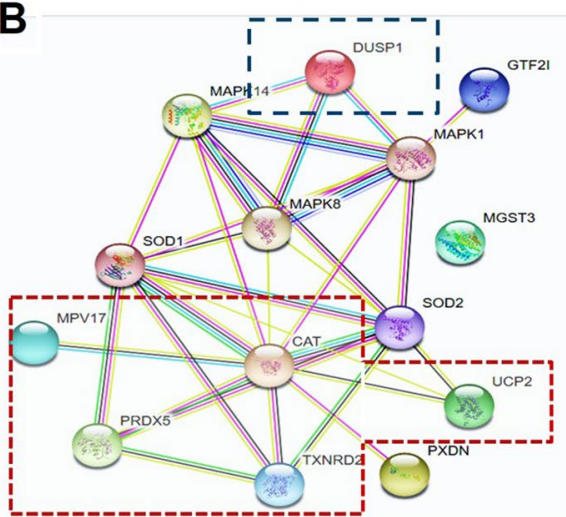

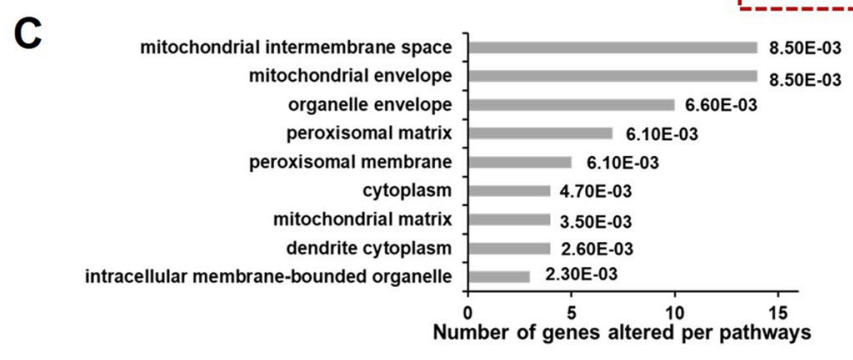

Fig. 5 Gene expression profile of oxidative stress and antioxidant defense in lung cell line exposed to CBNP and CBNP+W7. a List of genes common in 2 groups (CBNP and CBNP+W7) with a fold changes $>1.5$ in $\mathrm{CB}$ exposed cells and a fold change of $<1.5$ in $\mathrm{CB}+\mathrm{W} 7$. b Potential protein-protein interactions of all differentially expressed genes $(P<0.05)$ associated with CBNP exposure vs $\mathrm{CBNP}+\mathrm{W} 7$ as suggested by the STRING 9 database and web resources. Gene names were loaded into the STRING tool (http:// string-db.org/), and analyzed using the standard settings (medium

increase is an effect of different ROS species generated and is not dependent on an individual chemical species only. Other than ROS generation, CBNP exposure in A549 cells also exhibited a transient increase in calcium levels, as also observed in other studies (Holme et al. 2019). A slight disturbance in calcium homeostasis was observed already after $3 \mathrm{~h}$ of exposure, which increased consistently over $6 \mathrm{~h}$, and remained consistent even after $24 \mathrm{~h}$ exposure. Incubation with calcium chelators BAPTA and verapamil decreased the calcium levels of the cells, indicating the involvements of both extra and intracellular calcium sources.

Additionally, to examine whether CBNP-induced disturbance in ROS and calcium were interrelated, ROS measurements were carried out in presence of calcium chelators BAPTA and verapamil. While a significant increase in ROS levels was observed in CBNP exposed cells, these were reduced by $32 \%$ in BAPTA and $30 \%$ verapamil pretreated cells, suggesting the involvement of calcium signaling in increased ROS levels as observed upon CBNP exposure. However, the pretreatment was not able to eliminate the ROS level to basal levels as compared to control cells, suggesting a contribution of another calcium-independent pathway in overall ROS confidence, network depth 1 , no additional white nodes). The color of the connecting lines between two protein species encodes the source of the information: experimental data (rose), databases (light blue), co-expression data (black), co-occurrence data (dark blue), and text mining. (green) The nodes of interest are marked in colored boxes. c Cellular component enrichment analysis of screened proteins. The bar graph represents the number of genes enriched per cellular components of the cell. $\left({ }^{*} P<0.05\right.$, FDR (false discovery rate) corrected)

levels upon CBNP exposure. Furthermore, pretreatment of cells with the antioxidants NAC and Trolox suppressed the ROS generation but were unable to modulate calcium signaling increased by CBNP exposure. The results of the study pointed toward the role of calcium signaling in ROS generation upon CBNP exposure.

\section{The interplay of calcium and ROS signaling system}

Few studies have recognized a mutual and complex interplay between calcium and ROS signaling systems essential for the proper functioning of cellular signaling networks (Görlach et al. 2015; Hempel and Trebak 2017; Yan et al. 2006). It is now clear that sub-toxic levels of ROS act as signaling molecules, critical for various cellular processes including calcium signaling (Gordeeva et al. 2003; Görlach et al. 2015). By modulation of various extra and intracellular calcium channels and receptors, ROS can effectively modulate calcium signaling and hence its homeostasis (Feno et al. 2019). Calcium, on the other hand, is known to regulate 
several cellular functions, including the ones involved in the generation of ROS, particularly by mitochondria in the form of mitochondrial ROS (Adam-Vizi and Starkov 2010).

\section{CBNP-associated mitochondrial dysfunctions}

Since mitochondria are an integral part of $\mathrm{Ca}^{2+}$-mediated signal transduction cascades, mitochondria can take up, buffer, and release $\mathrm{Ca}^{2+}$ ions to shape cytosolic $\mathrm{Ca}^{2+}$ transients, as well as stimulate ATP and mitochondrial ROS production (DeLuca and Engstrom 1961). Moreover, threedimensional conformational changes in the respiratory chain complexes due to calcium ions have been reported to increase the generation of mitochondrial ROS (Brookes et al. 2004). Our initial studies revealed a substantial increase in ROS upon CBNP triggered by calcium. Also, a substantial amount of increase in mitochondrial calcium was observed (Fig. 1e, f). To analyze if CBNP exposure also led to mitochondrial dysfunction in these cell lines, MMP and mitochondrial ROS measurements were carried out. The investigation revealed hyperpolarization of mitochondria as soon as after $6 \mathrm{~h}$ of exposure in cells exposed to high CBNP (63 to $250 \mu \mathrm{g} / \mathrm{mL}$ ) (Fig. 4a), which stayed even after $24 \mathrm{~h}$ (Fig. 4b). Interestingly, there are studies, suggesting that hyperpolarization of mitochondria is significantly influenced by the elevated cellular ROS levels. It is therefore likely that the CBNP-mediated increased ROS levels (especially at high concentrations, Fig. 1a) in A549 cells are responsible for the observed hyperpolarization of mitochondria. The elevated hyperpolarization is further known to cause ROS overproduction, which further leads to mitochondrial dysfunction and more ROS production, thus causing cell damage. The results are supported by a significant amount of mitochondrial ROS measured at all the exposure (nominal) concentrations (Fig. 4c, d).

To investigate further an underlying mechanism for the interaction of calcium and ROS in the mitochondria, we have focused on the role of calmodulin that is known to contribute to cellular dysfunction by promoting defective intracellular $\mathrm{Ca}^{2+}$ handling, including mitochondrial $\mathrm{Ca}^{2+}$ overload.

\section{The possible role of calmodulin in CBNP-induced oxidative stress and mitochondrial dysfunction}

The increase in intracellular calcium concentration has been demonstrated to modulate cellular function by the activity of several calcium-binding proteins (Bagur and Hajnóczky 2017). Calmodulin is also one of such known proteins, forming complexes with calcium and thus participating in the regulation of several signal transduction pathways (Swulius and Waxham 2008). The first evidence for the role of calmodulin in oxidative stress in our study was the $50 \%$ reduction in ROS in cells pretreated with calmodulin.

To gain a deeper insight into the possible mechanism, a wide screening for 84 different genes involved in oxidative stress was performed in presence and absence of $\mathrm{CaM}$ inhibitor W-7. A set of nine genes were identified, which were upregulated after exposure to CBNP. However, upon pretreatment with the CaM inhibitor the same set of genes were found to be downregulated, indicating toward its role in the regulation of oxidative stress. Bioinformatic analysis of these nine genes via STRING analysis underlined among other the pathways involved in the response to oxidative stress. The mitochondria were highlighted as a main cellular component for most of the gene regulated (five genes i.e. CAT, MPV17, PRDX5, TXNRD2, and UCP2, Fig. 5c), thus supporting the gathered cytotoxicity data, exhibiting an increase in mitochondrial ROS, and hyperpolarization of mitochondria upon CBN nanoparticle exposure (Fig. 4). The ubiquitous protein $\mathrm{CaM}$ is found mainly in the cytoplasm, nucleus and plasma membrane, but few studies have also reported its presence in mitochondria. The role of calcium-activated protein $\mathrm{CaM}$ in mitochondrial dysfunction, which further leads to exacerbation of mitochondrial ROS, thus eventually leading to cell death, has been reported in few studies (Hajimohammadreza et al. 1995; Lee et al. 2005; Liu and Templeton 2007; Odagiri et al. 2009; Takano et al. 2003; Toledo et al. 2014). Regulation of the five mitochondrial proteins in the present study points toward the mitochondrial dysfunction that the cells undergo when exposed to the nanoparticles.

Another interesting observation was the regulation of the DUSP1 gene. Dual specificity phosphatases 1 (DUSP1) belongs to a family of stress-induced enzymes that plays an important role in feedback inhibition of mitogen-activated protein kinases (Caunt and Keyse 2013), one of the pathways highlighted during STRING analysis (Fig. 5).

MAPKs are components of the signaling cascades comprising extracellular signal-regulated kinase (ERK), c-Jun-NH2 kinase (JNK) and p38 by which these control a range of fundamental processes including inflammation and apoptosis (Cargnello and Roux 2011). MAPK signaling is also involved in the biological response to organic compounds, particularly carbon black (Donaldson et al. 2003; Dong and Ma 2015; Yuan et al. 2020).

DUSP1 seems to be part of a negative feedback loop controlling the immune response. It was reported that in A549 cells, IL- $1 \beta$ rapidly induced DUSP1 expression with subsequent inhibition of MAPKs and inflammatory gene expression (Shah et al. 2014). IL-1 $\beta$ is a key driver of acute inflammation after cellular damaging, by initiating downstream signaling together with TNF- $\alpha$, it initiates 
production of chemokines by epithelial cells (Di Paolo and Shayakhmetov 2016). And it is quite conceivable that feedback mechanisms are activated at the same time to prevent an excessive immune response. Along with it, DUSP1 also appears to play a role in apoptosis due to oxidative stress (Jin et al. 2018). Further investigations are certainly necessary to elucidate the mode of action of calcium in nanoparticle-mediated ROS toxicity, but nevertheless these results underline the multifaceted role of calcium and calmodulin in the cellular response to CBNP.

\section{Conclusion}

The modulation of intracellular calcium and oxidative stress upon exposure to CBNP has been observed in several studies. Increasing evidence suggests a mutual interplay between calcium and ROS signaling systems upon exposure to CBNP; however, the relevant pathways that contribute to such interplay remain poorly understood. With our study, it was presented that in CBNP exposed alveolar cells, calcium is the main driver of the biological response, as the changes in $\mathrm{Ca}^{2+}$ levels significantly reduced ROS formation. On the other hand, the reduction of ROS had no effect on calcium overload. The hypothesis was supported by studies on the role of calmodulin in this context.

For a better understanding as to how calcium and calcium-binding protein CaM regulates CBNP-mediated oxidative stress, an in-depth gene array analysis of genes involved in oxidative stress was performed in presence or absence of CaM. Interestingly, nine oxidative stress-related genes were found downregulated in absence of calcium-regulated gene $\mathrm{CaM}$, therefore indicating the role of calcium-regulated $\mathrm{CaM}$ in CBNP nanoparticles mediated oxidative stress. Further, pathway analysis revealed five out of the nine identified genes were mitochondrial oxidative stress genes, hence pointing toward the role of mitochondria ROS upon CBNP exposure. The finding was further supported by the detection of a significant amount of mitochondrial ROS in CBNP exposed cells. The study thus points toward how CBNPmediated lung toxicity is a result of both disturbances in calcium and ROS homeostasis, and thus be given full consideration while designing new strategies for its prevention.

Supplementary Information The online version contains supplementary material available at https://doi.org/10.1007/s00204-021-03032-0.

Funding Open Access funding enabled and organized by Projekt DEAL.. The authors gratefully acknowledge funding of the Staedtler Stiftung, Bavarian Equal Opportunities Sponsorship-Förderung von Frauen in Forschung und Lehre (FFL)-Promoting Equal opportunities for Women in Research and Teaching in the framework of the German Excellence Initiative. The funders have no role in study design, data collection and analysis, decision to publish, or preparation of the manuscript.

\section{Declarations}

Conflict of interest The author declares no conflict of interests.

Open Access This article is licensed under a Creative Commons Attribution 4.0 International License, which permits use, sharing, adaptation, distribution and reproduction in any medium or format, as long as you give appropriate credit to the original author(s) and the source, provide a link to the Creative Commons licence, and indicate if changes were made. The images or other third party material in this article are included in the article's Creative Commons licence, unless indicated otherwise in a credit line to the material. If material is not included in the article's Creative Commons licence and your intended use is not permitted by statutory regulation or exceeds the permitted use, you will need to obtain permission directly from the copyright holder. To view a copy of this licence, visit http://creativecommons.org/licenses/by/4.0/.

\section{References}

Abdal Dayem A, Hossain MK, Lee SB et al (2017) The role of reactive oxygen species (ROS) in the biological activities of metallic nanoparticles. Int J Mol Sci 18(1):120. https://doi.org/10.3390/ ijms 18010120

Adam-Vizi V, Starkov AA (2010) Calcium and mitochondrial reactive oxygen species generation: how to read the facts. J Alzheimer's Disease. 20(Suppl 2):S413-S426. https://doi.org/10.3233/ JAD-2010-100465

Aldini G, Altomare A, Baron G et al (2018) N-Acetylcysteine as an antioxidant and disulphide breaking agent: the reasons why. Free Radical Res 52(7):751-762. https://doi.org/10.1080/10715762. 2018.1468564

Bagur R, Hajnóczky G (2017) Intracellular Ca(2+) Sensing: its role in calcium homeostasis and signaling. Mol Cell 66(6):780-788. https://doi.org/10.1016/j.molcel.2017.05.028

Brookes PS, Yoon Y, Robotham JL, Anders MW, Sheu S-S (2004) Calcium, ATP, and ROS: a mitochondrial love-hate triangle. Am J Physiol Cell Physiol 287(4):C817-C833. https://doi.org/10.1152/ ajpcell.00139.2004

Cargnello M, Roux PP (2011) Activation and function of the MAPKs and their substrates, the MAPK-activated protein kinases. Microbiol Mol Biol Rev 75(1):50-83. https://doi.org/10.1128/MMBR. 00031-10

Caunt CJ, Keyse SM (2013) Dual-specificity MAP kinase phosphatases (MKPs): shaping the outcome of MAP kinase signalling. FEBS J 280(2):489-504. https://doi.org/10.1111/j.1742-4658.2012. 08716.x

DeLuca HF, Engstrom GW (1961) Calcium uptake by rat kidney mitochondria. Proc Natl Acad Sci USA 47(11):1744-1750

Di Paolo NC, Shayakhmetov DM (2016) Interleukin $1 \alpha$ and the inflammatory process. Nat Immunol 17(8):906-913. https://doi.org/10. 1038/ni.3503

Donaldson K, Stone V, Borm PJA et al (2003) Oxidative stress and calcium signaling in the adverse effects of environmental particles (PM10). Free Radical Biol Med 34(11):1369-1382. https://doi. org/10.1016/S0891-5849(03)00150-3

Dong J, Ma Q (2015) Advances in mechanisms and signaling pathways of carbon nanotube toxicity. Nanotoxicology 9(5):658-676. https://doi.org/10.3109/17435390.2015.1009187

Feno S, Butera G, Vecellio Reane D, Rizzuto R, Raffaello A (2019) Crosstalk between calcium and ROS in pathophysiological conditions. Oxid Med Cell Longev 2019:9324018-9324018. https://doi. org/10.1155/2019/9324018 
Fu PP, Xia Q, Hwang H-M, Ray PC, Yu H (2014) Mechanisms of nanotoxicity: generation of reactive oxygen species. J Food Drug Anal 22(1):64-75. https://doi.org/10.1016/j.jfda.2014.01.005

Gonzalez L, Lison D, Kirsch-Volders M (2008) Genotoxicity of engineered nanomaterials: a critical review. Nanotoxicology 2(4):252273. https://doi.org/10.1080/17435390802464986

Gordeeva AV, Zvyagilskaya RA, Labas YA (2003) Cross-talk between reactive oxygen species and calcium in living cells. Biochemistry (Mosc) 68(10):1077-1080. https://doi.org/10.1023/a:1026398310 003

Görlach A, Bertram K, Hudecova S, Krizanova O (2015) Calcium and ROS: a mutual interplay. Redox Biol 6:260-271. https://doi.org/ 10.1016/j.redox.2015.08.010

Gustafson HH, Holt-Casper D, Grainger DW, Ghandehari H (2015) Nanoparticle uptake: the phagocyte problem. Nano Today 10(4):487-510. https://doi.org/10.1016/j.nantod.2015.06.006

Hajimohammadreza I, Probert A, Coughenour L et al (1995) A specific inhibitor of calcium/calmodulin-dependent protein kinase-II provides neuroprotection against NMDA- and hypoxia/hypoglycemia-induced cell death. J Neurosci 15(5):4093-4101. https://doi. org/10.1523/jneurosci.15-05-04093.1995

Hamad I, Arda N, Pekmez M, Karaer S, Temizkan G (2010) Intracellular scavenging activity of Trolox (6-hydroxy-2,5,7,8-tetramethylchromane-2-carboxylic acid) in the fission yeast, Schizosaccharomyces pombe. J Nat Sci Biol Med 1(1):16-21. https://doi.org/ 10.4103/0976-9668.71667

Hempel N, Trebak M (2017) Crosstalk between calcium and reactive oxygen species signaling in cancer. Cell Calcium 63:70-96. https://doi.org/10.1016/j.ceca.2017.01.007

Holme J, Brinchmann B, Le Ferrec E, Lagadic-Gossmann D, Ovrevik J (2019) Combustion particle-induced changes in calcium homeostasis: a contributing factor to vascular disease? Cardiovasc Toxicol. https://doi.org/10.1007/s12012-019-09518-9

Huang Y-W, Cambre M, Lee H-J (2017) The toxicity of nanoparticles depends on multiple molecular and physicochemical mechanisms. Int J Mol Sci 18(12):2702. https://doi.org/10.3390/ijms18122702

Jeevanandam J, Barhoum A, Chan YS, Dufresne A, Danquah MK (2018) Review on nanoparticles and nanostructured materials: history, sources, toxicity and regulations. Beilstein J Nanotechnol 9:1050-1074. https://doi.org/10.3762/bjnano.9.98

Jin Q, Li R, Hu N et al (2018) DUSP1 alleviates cardiac ischemia/ reperfusion injury by suppressing the Mff-required mitochondrial fission and Bnip3-related mitophagy via the JNK pathways. Redox Biol 14:576-587. https://doi.org/10.1016/j.redox.2017.11.004

Lee CS, Park SY, Ko HH, Song JH, Shin YK, Han ES (2005) Inhibition of MPP+-induced mitochondrial damage and cell death by trifluoperazine and W-7 in PC12 cells. Neurochem Int 46(2):169-178. https://doi.org/10.1016/j.neuint.2004.07.007

Liu Y, Templeton DM (2007) Cadmium activates CaMK-II and initiates CaMK-II-dependent apoptosis in mesangial cells. FEBS Lett 581(7):1481-1486. https://doi.org/10.1016/j.febslet.2007.03.003

Madl AK, Plummer LE, Carosino C, Pinkerton KE (2014) Nanoparticles, lung injury, and the role of oxidant stress. Annu Rev Physiol 76:447-465. https://doi.org/10.1146/annurev-physi ol-030212-183735

Manke A, Wang L, Rojanasakul Y (2013) Mechanisms of nanoparticle-induced oxidative stress and toxicity. Biomed Res Int 2013:942916-942916. https://doi.org/10.1155/2013/942916

Niranjan R, Thakur AK (2017) The toxicological mechanisms of environmental soot (black carbon) and carbon black: focus on oxidative stress and inflammatory pathways. Front Immunol. https:// doi.org/10.3389/fimmu.2017.00763

Odagiri K, Katoh H, Kawashima H et al (2009) Local control of mitochondrial membrane potential, permeability transition pore and reactive oxygen species by calcium and calmodulin in rat ventricular myocytes. J Mol Cell Cardiol 46(6):989-997. https:// doi.org/10.1016/j.yjmcc.2008.12.022

Prada D, Zhong J, Colicino E et al (2017) Association of air particulate pollution with bone loss over time and bone fracture risk: analysis of data from two independent studies. Lancet Planet Health 1(8):e337-e347. https://doi.org/10.1016/S2542-5196(17)30136-5

Saputra D, Yoon J-H, Park H et al (2014) Inhalation of carbon black nanoparticles aggravates pulmonary inflammation in mice. Toxicol Res 30(2):83-90. https://doi.org/10.5487/TR.2014.30.2.083

Shah S, King EM, Chandrasekhar A, Newton R (2014) Roles for the mitogen-activated protein kinase (MAPK) phosphatase, DUSP1, in feedback control of inflammatory gene expression and repression by dexamethasone. J Biol Chem 289(19):13667-13679. https://doi.org/10.1074/jbc.M113.540799

Sharma M (2010) Understanding the mechanism of toxicity of carbon nanoparticles in humans in the new millennium: a systemic review. Indian J Occup Environ Med 14(1):3-5. https://doi.org/ 10.4103/0019-5278.64607

Stone V, Tuinman M, Vamvakopoulos JE et al (2000) Increased calcium influx in a monocytic cell line on exposure to ultrafine carbon black. Eur Respir J 15(2):297-303

Swulius MT, Waxham MN (2008) Ca(2+)/calmodulin-dependent protein kinases. Cell Mol Life Sci 65(17):2637-2657. https://doi.org/ 10.1007/s00018-008-8086-2

Takano H, Fukushi H, Morishima Y, Shirasaki Y (2003) Calmodulin and calmodulin-dependent kinase II mediate neuronal cell death induced by depolarization. Brain Res 962(1):41-47. https://doi. org/10.1016/S0006-8993(02)03932-X

Toledo FD, Pérez LM, Basiglio CL, Ochoa JE, Sanchez Pozzi EJ, Roma MG (2014) The Ca2+-calmodulin-Ca2+/calmodulin-dependent protein kinase II signaling pathway is involved in oxidative stressinduced mitochondrial permeability transition and apoptosis in isolated rat hepatocytes. Arch Toxicol 88(9):1695-1709. https:// doi.org/10.1007/s00204-014-1219-5

Uddin M (2017) Recent progress on synthesis, characterization and applications of carbon black nanoparticles. $\mathrm{p} 40$

Umezawa M, Onoda A, Korshunova I et al (2018) Maternal inhalation of carbon black nanoparticles induces neurodevelopmental changes in mouse offspring. Part Fibre Toxicol 15(1):36. https:// doi.org/10.1186/s12989-018-0272-2

Vesterdal LK, Folkmann JK, Jacobsen NR et al (2010) Pulmonary exposure to carbon black nanoparticles and vascular effects. Part Fibre Toxicol 7:33-33. https://doi.org/10.1186/1743-8977-7-33

von Mering C, Huynen M, Jaeggi D, Schmidt S, Bork P, Snel B (2003) STRING: a database of predicted functional associations between proteins. Nucleic Acids Res 31(1):258-261. https://doi.org/10. 1093/nar/gkg034

Wada T, Penninger JM (2004) Mitogen-activated protein kinases in apoptosis regulation. Oncogene 23(16):2838-2849. https://doi. org/10.1038/sj.onc.1207556

Yan Y, Wei C-1, Zhang W-r, Cheng H-p, Liu J (2006) Cross-talk between calcium and reactive oxygen species signaling. Acta Pharmacol Sin 27(7):821-826. https://doi.org/10.1111/j.17457254.2006.00390.x

Yuan X, Nie W, He Z et al (2020) Carbon black nanoparticles induce cell necrosis through lysosomal membrane permeabilization and cause subsequent inflammatory response. Theranostics 10(10):4589-4605. https://doi.org/10.7150/thno.34065

Publisher's Note Springer Nature remains neutral with regard to jurisdictional claims in published maps and institutional affiliations. 